\title{
Reinforcing Effects of Seaweed Nanoparticles in Agar- based Biopolymer Composite: Physical, Water Vapor Barrier, Mechanical, and Biodegradable Properties
}

\author{
Rudi Dungani, ${ }^{\mathrm{a}, *}$ Ihak Sumardi, ${ }^{\mathrm{a}}$ Yoyo Suhaya, ${ }^{\mathrm{a}}$ Pingkan Aditiawati, ${ }^{\mathrm{a}}$ Safar Dody, ${ }^{\mathrm{b}}$ Enih
} Rosamah, ${ }^{\mathrm{c}}$ Md. Nazrul Islam, ${ }^{\mathrm{d}}$ Sri Hartati, ${ }^{\mathrm{e}}$ and Tati Karliati ${ }^{\mathrm{a}}$

\begin{abstract}
In recent times, the indiscriminate disposal of post-consumer plastic packaging material has received global attention. There is a need to develop an alternative packaging material from bio-based polymers to reduce plastic waste pollution. This work studied the effects of loading seaweed nanoparticles into an agar matrix by analyzing the physical, mechanical, water vapor barrier, and biodegradation properties, as well as the surface morphological properties of biopolymer composite. The results showed that the addition of seaweed nanoparticles in the biopolymer matrix improved the properties of the agar-based biopolymer composite, except for the water vapor barrier properties of the biopolymer composite. The biopolymer composite film loaded with $6 \mathrm{w} / \mathrm{w} \%$ seaweed nanoparticles appeared to achieve the highest mechanical strength. In addition, scanning electron microscopy analysis verified that the $6 \% \mathrm{w} / \mathrm{w} \%$ seaweed nanoparticles biopolymer composite showed a homogenous surface morphology and had a strong adhesion on the interfaces of the filler and matrix. The samples had a desirable density of $0.0131 \mathrm{~cm}^{-1} \mathrm{~g}^{-1}$ and a desirable biodegradability when $8 \mathrm{w} / \mathrm{w} \%$ nanoparticles was used. This study verified that seaweed nanoparticles are compatible with agar matrix in terms of the enhancement of biopolymer composite properties.
\end{abstract}

Keywords: Reinforcement; Nanofiller; Biopolymer composite; Kappaphycus alvarezii; Agar

Contact information: a: School of Life Sciences and Technology, Institut Teknologi Bandung, Bandung, West Java 40132 Indonesia; b: Research Center for Oceanography, Indonesian Institute of Sciences, Jakarta 14430 Indonesia; ; c: Faculty of Forestry, Mulawarman University, Campus Gunung Kelua, Samarinda 75119, East Kalimantan, Indonesia; d: Forestry and Wood Technology Discipline, Khulna University, Khulna 9208 Bangladesh; e: Faculty of Agriculture, Padjadjaran University, Bandung 45363 Indonesia;

* Corresponding author: rudi@ sith.itb.ac.id

\section{INTRODUCTION}

The environmental pollution caused by the disposal of synthetic plastic packaging materials, including high- and low-density polyethylene (HDPE and LDPE) bags, films, and sachets, has received global attention. A substantial amount of synthetic plastics is polluting the environment, causing further problems through their incineration and decreasing landfill capacities (Leja and Lewandowicz 2010; Mierzwa-Hersztek et al. 2019). Over 50 million tonnes of synthetic plastic wastes are generated yearly in Europe, the United States, and Japan (Abdel-Shafy and Mansour 2018). Meanwhile, the Indonesian Olefin Aromatic Plastic Industry Association (INAPLAS) reported that plastic waste in Indonesia has reached 5 million tons per year and 3.2 million tons of them were thrown into the sea (Supriadi 2016). 
Nowadays, the demands for synthetic plastics continue to increase, especially for food packaging purposes. These packaging are preferred for their durability; however, they are non-biodegradable and are mostly non-environmental-friendly. In order to reduce plastic waste, the development of environmentally friendly packaging has been started, e.g., packaging using polysaccharide-based biopolymer material (Shankar and Rhim 2016; Hubbe et al. 2017). The challenge of using bio-based polymers as a packaging material lies in their weakness, since they have poor mechanical and barrier properties (Sorrentino et al. 2016). Therefore, natural fibers have been added to the polymer matrix as reinforcing fillers during biocomposites production to enhance strength and biodegradability (Usman et al. 2016). Among other natural fibers used to develop biodegradable biofilms, seaweed is considered more preferable due to its abundance and low cost (Huq et al. 2012; Abdul Khalil et al. 2016, 2017a,b, 2018).

Seaweed is one of the leading fishery products in Indonesia. According to Food and Agriculture Organization, Indonesia is the second-largest producer of cultured seaweed after China, with a total production of 9.9 million tons worth 324.84 million USD in 2018 (Food Agriculture Organization Fisheries and Aquaculture Information and Statistics Branch FAO-FIGIS 2019). According to Shia et al. (2015), Indonesia's geographical condition makes it possible to produce seaweed throughout the year. The abundance of produced seaweed has made it possible to process it into other products with a higher value, e.g., as a filler in the bio-based polymer.

Natural fibers, e.g., cellulose, need modification to be a functional material, such as by reducing the size of the cellulose fiber to a nanometer scale (Phanthong et al. 2018). The addition of nanoparticles could increase intermolecular interaction, e.g., hydrogen bonds, in the film matrix, reducing the film defects (Shankar and Rhim 2016). The potential of seaweed as a novel filler in polypropylene composites was studied by Luan et al. (2010), who reported that the addition of seaweed fiber was successfully incorporated in the PP matrix in terms of mechanical reinforcement. Further studies by Merino and Alvarez (2020) reported that the seaweed microparticle which is incorporated in the thermoplastic starch (TPS)-chitosan $(\mathrm{CH})$ matrix showed good interaction. Its addition produced an increase in the tensile strength and a slight increase in the elongation at break.

Finally, a study on seaweed-based nanoparticles was used to prepare and test the effects of the inclusion of a seaweed nanoparticles filler in agar-based biopolymer composite on enhancing physical, water vapor barrier, mechanical, and biodegradable properties.

Hence, the present work aimed to develop a composite film based on several physical and mechanical analytical techniques, and to determine the effects of the presence of seaweed nanoparticles on the properties of biopolymer composites through various characterizations.

\section{EXPERIMENTAL}

\section{Materials and Chemicals}

Red seaweed (Kappaphycus alvarezii) was obtained from Ternate, North Maluku, Indonesia. The seaweed was cleaned to remove sand and other impurities and sundried for 5 d. Distilled water, ethanol, agar, and glycerol were purchased from PT. Bratachem (Jakarta, Indonesia). All chemicals are reagent-grade and used as received. 


\section{Methods}

\section{Preparation of the seaweed nanoparticles}

Dried seaweed was ground into granular particles using a Wiley mill (Thomas Model 4 Wiley® Cutting Mill, United States) and sieved (60-mesh size) to separate the micro-size particles. The micro-size dried seaweed particles (DSP) were further ground using a grinder/refiner, followed by high-energy ball milling (High Energy Ball Mill Emax, Retsch, Germany) for $30 \mathrm{~h}$ at $170 \mathrm{rev} / \mathrm{min}^{-1}$ (Swami et al. 2009). The ball mill was loaded with a ball to powder weight ratio of 10 to 1 in a stainless-steel chamber with different sized stainless-steel balls, i.e., $19 \mathrm{~mm}, 12.7 \mathrm{~mm}$, and $9.5 \mathrm{~mm}$ diameters). The nanoparticles seaweed (NPS) was kept under high-temperature condition $\left(250^{\circ} \mathrm{C}\right)$ in a drying oven for $24 \mathrm{~h}$ to prevent agglomeration and kept in a dry place to avoid contact with moisture.

The particle size distribution of the NPS was measured on a MALVERN Zetasizer Ver. 6.11 (MAL 1029406, Malvern, United Kingdom) via dynamic light scattering measurements with a $532 \mathrm{~nm}$ laser. The measurement of the average particle size was automatically repeated three times based on the internal settings of the equipment.

The crystallinity index analyzed by X-ray diffraction (PHILIPS PW 1050 X-pert Diffractometer, Germany) using $\mathrm{CuK} \alpha$ radiation $(\mathrm{K} \alpha=1.54 \AA)$ with the accelerating voltage of $40 \mathrm{kV}$ and a current of $25 \mathrm{~m} \AA$.

The NFS was suspended into $200 \mathrm{~mL}$ of distilled water and then heated for $15 \mathrm{~min}$ at a temperature of $121^{\circ} \mathrm{C}$ and a pressure of $1 \mathrm{~atm}$. Then, the biomass filtrate and pulp were produced via filtration. The filtrate of the seaweed suspension solution was then purified with $200 \mathrm{~mL}$ of $95 \%$ ethanol and separated with gauze and Whatman paper number 2 . The resulting precipitate was dried at $50{ }^{\circ} \mathrm{C}$.

\section{Preparation of the biopolymer composite with nanoparticle seaweed}

Preparation of the biopolymer composite was carried out according to the solution casting method based on evaporation at room temperature, as described by Hubbe et al. (2017). A solution was prepared by dissolving $1 \%$ (v/v distilled water) of agar in $200 \mathrm{~mL}$ of distilled water with $30 \%$ (w/w agar) of glycerol as a plasticizer. Seaweed nanoparticles were added into the solution as a filler at different loadings $(0 \%, 4 \%, 6 \%$, and $8 \%)$, based on the weight of the agar (w/w). The solution was heated to $90{ }^{\circ} \mathrm{C}$ and stirred occasionally for $1 \mathrm{~h}$ to obtain a homogenous solution. The solution was then poured into a Teflon plate (20 cm in diameter) and placed in a ventilated oven at $40{ }^{\circ} \mathrm{C}$ for $24 \mathrm{~h}$. All peeled-off biopolymer composites were further conditioned in a chamber at a relative humidity $(\mathrm{RH})$ of $50 \%$ before testing.

\section{Physical properties}

The thickness was measured according to ASTM standard D374-99 (1999) using a precision digital micrometer (Mitutoyo, Kanagawa, Japan) to the nearest $0.001 \mathrm{~mm}$.

The density for each of the biopolymer composites was determined according to Marvdashti et al. (2017), with slight modifications. The biopolymer composites were cut into $3 \mathrm{~cm} \times 3 \mathrm{~cm}$ pieces and were placed in a desiccator with silica gel at an $\mathrm{RH}$ of $0 \%$ for a week. The films were then weighed, and the density was calculated using Eq. 1,

$$
D=X / A \times m
$$

where $A$ is the film area $\left(\mathrm{cm}^{2}\right), m$ is the film dry mass $(\mathrm{g})$, and $X$ is the film thickness $(\mathrm{cm})$. 


\section{Water vapor barrier properties}

The biopolymer composites were cut into a circle, according to the area of the cup $\left(43 \mathrm{~cm}^{2}\right)$. The permeability cups containing $16 \mathrm{~mL}$ of distilled water were mounted over the cups and sealed with the selected films; this was carried out in a controlled humidity chamber at a temperature of $25^{\circ} \mathrm{C}$ and an $\mathrm{RH}$ of $50 \%$ for $6 \mathrm{~h}$. The changes in water weight were recorded every hour.

The graph of the changes in cup weight versus time was plotted and calculated via linear regression $\left(\mathrm{R}^{2}\right.$ was greater than 0.95$)$. The water vapor transmission rate (WVTR) was determined using Eq. 2,

$$
\text { WVTR }=\text { slope/area }
$$

\section{Mechanical properties}

The tensile strength (TS) and percentage of elongation $(\% \mathrm{E})$ of the biopolymer composites were measured on a $2.5 \mathrm{kN}$ Lloyd tensile tester according to the ASTM standard D-882-02 (2002), with slight modifications. The biopolymer composites were cut into $10 \mathrm{~cm}$ length $\mathrm{x} 1 \mathrm{~cm}$ width strips and then were tested using a tensile tester equipped with a $5 \mathrm{~kg}$ load cell. The initial gauge length was set at $50 \mathrm{~mm}$, and the crosshead speed was fixed at $50 \mathrm{~mm} / \mathrm{min}$.

\section{Morphological properties}

Before observation, all specimens were placed on double-sided Scotch tape and coated with a thin gold ( $\mathrm{Au}$ ) layer using a sputter coater (Polaron SC515). The surface morphology of the oven-dried biopolymer composites ( $1 \mathrm{~cm} \mathrm{x} 1 \mathrm{~cm}$ size) was observed via a JEOL JSM6390LV scanning electron microscope model ZEISS (EVO MA10; Carl Zeiss SMT, Oberkochen, Germany), with an accelerated voltage of $15 \mathrm{kV}$ and a $200 \mathrm{x}$ magnification.

\section{Biodegradability properties}

The biodegradability test was adopted from ASTM standard D5988-18 (2018) with slight modification (Fig. 1).

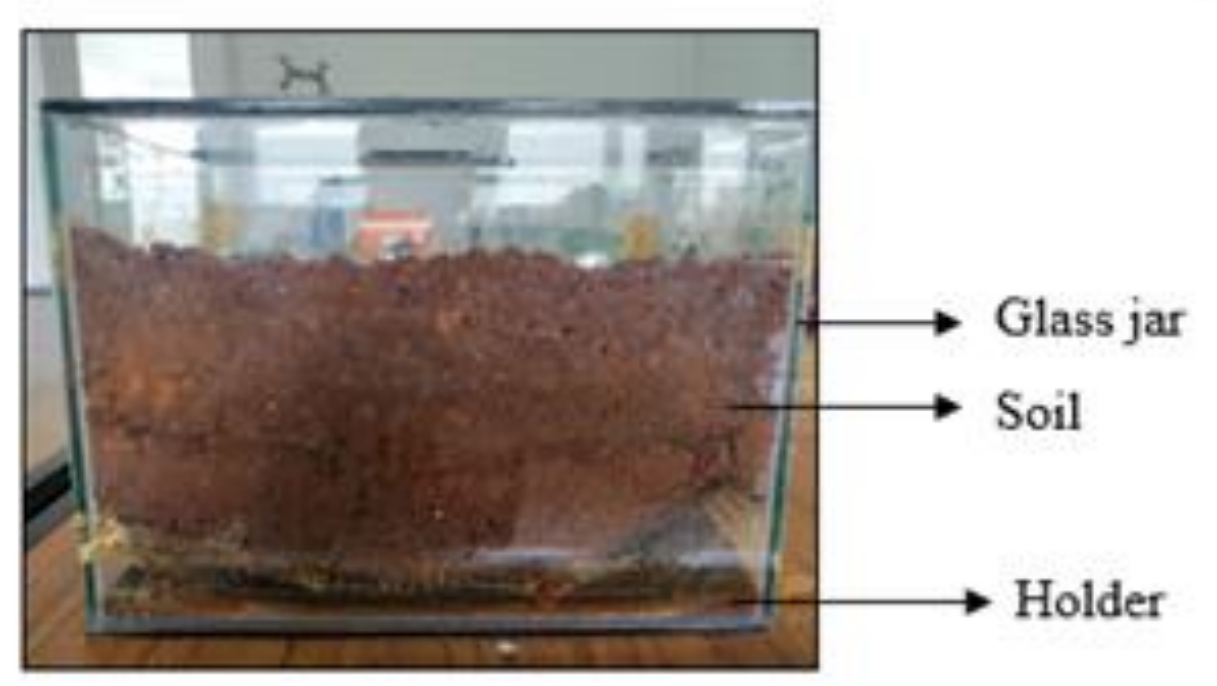

Fig. 1. Test assemblies of the soil buried test 
The biopolymer composites were cut into rectangular-shaped samples (100 $\mathrm{mm} \mathrm{x}$ $25 \mathrm{~mm} \times 15 \mathrm{~mm}$ ) and buried in the soil. The samples were exhumed every $7 \mathrm{~d}$, washed, dried, weighed, and placed back under the soil. The natural soil has a $90 \%$ water holding capacity (WHC), a soil moisture content of $50 \%$, and a soil $\mathrm{pH}$ of approximately 6 . The test was carried out for three weeks and the buried samples were then collected from the soil and the dirt removed via washing and drying. The degradation of the biopolymer composite samples was determined by the changes in weight, shape, dimension, and physical appearance. The degradation rate in the soil burial test was determined using Eq. 3 ,

$$
\text { Degradation rate }=\left(W_{1}-W_{\mathrm{H}}\right) / W_{1} \times 100 \%
$$

where $W_{\mathrm{H}}$ is the dry weight of the sample after being buried in the soil (mg), and $W_{1}$ is the initial dry weight of the sample (mg).

\section{RESULTS AND DISCUSSION}

\section{Characterization of Seaweed Nanoparticles}

The particle size distribution of the seaweed nanoparticles according to intensity covers a wide range of particles with symmetric behavior of curve (Fig. 2a). The diameter of the major portion of the particles ranged between $20.8 \mathrm{~nm}$ to $98.3 \mathrm{~nm}$, which covers $98.70 \%$ of the nanoparticles (Fig. 2a). The variation in the particle size resulted from the ball milling process. Thus, the results confirm that the seaweed particles can be classified as nanostructured materials, as defined by Koo (2006).
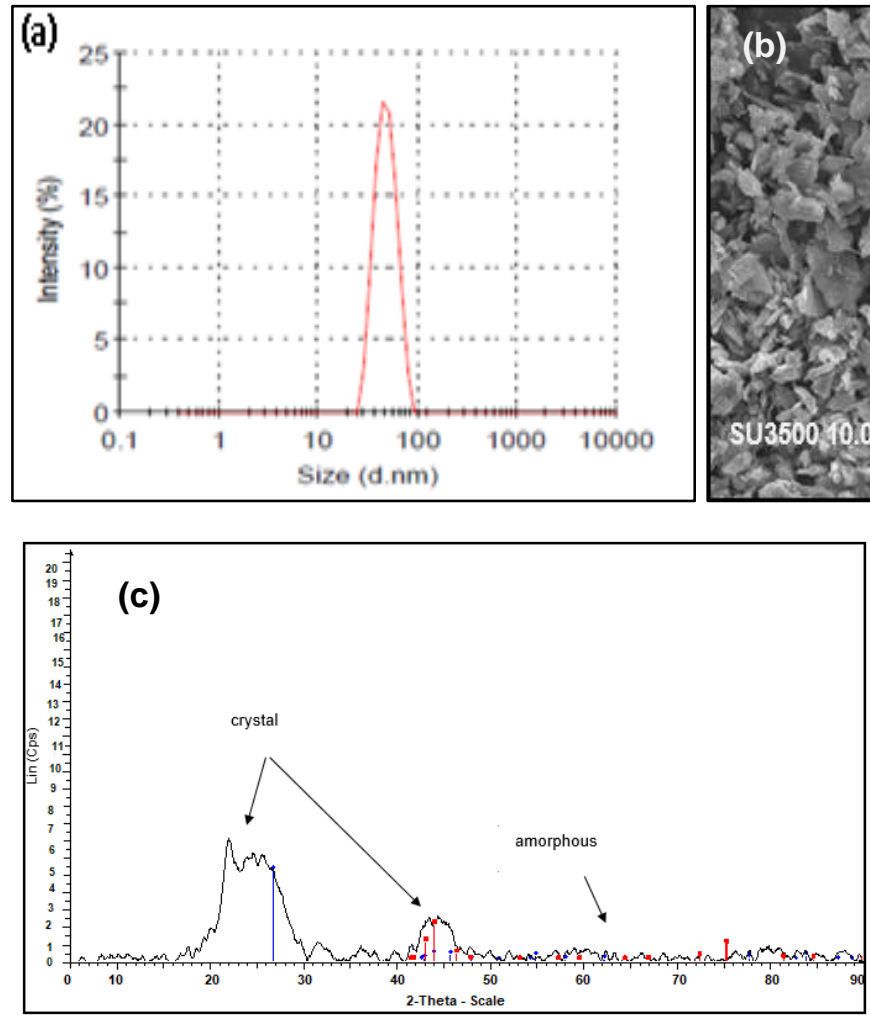

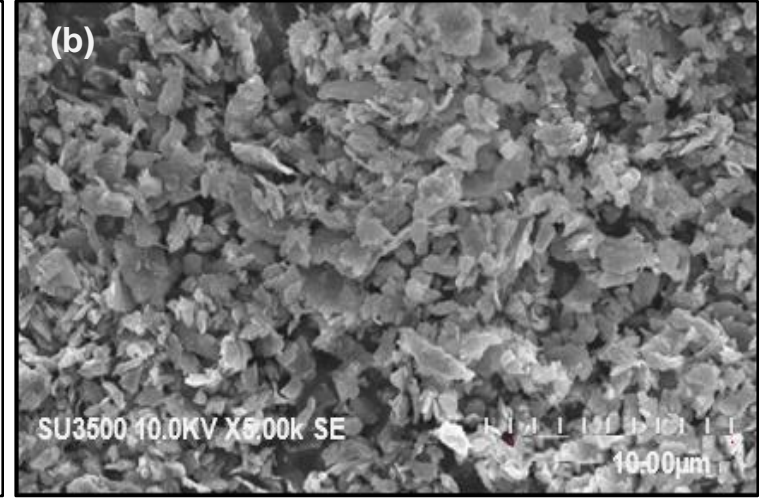

Fig. 2. The seaweed nanoparticles: (a) the particle size distribution according to intensity of the seaweed nanoparticles; (b) the seaweed nanoparticles surface morphologies taken with SEM; and (c) XRD diffraction patterns of seaweed nanoparticles 
The morphological observation of the seaweed particles obtained is shown in Fig. 2b. The scanning electron microscopy (SEM) micrograph revealed that the shape of the seaweed particle became angular, irregular, and crushed. This was due to the ball milling process, which caused the spherical structure of the seaweed to break down and the particle size to decrease to the nanoscale over time (Paul et al. 2007). The change in the structure of the seaweed nanoparticles makes them suitable to use as a filler material in composites. Along with the solid spheres, the irregular-shaped cellulose particles can be seen, since their size was larger. In addition, agglomerated spheres and irregularly shaped amorphous particles can be detected, which possibly resulted from inter-particle fusion (Fig. 2c). However, it was not possible to detect a single particle, even at higher magnifications, via SEM analysis, which might be related to the agglomeration of the particles and the restriction of SEM analysis itself.

\section{Physical Properties}

The film thickness was measured before the mechanical and water barrier tests. The thickness of the blank agar biopolymer composite and agar-seaweed nanoparticles biopolymer are displayed in Table 1 . The average thickness of the control biopolymer composite was $0.074 \mathrm{~mm}$, which was lower than noted in previous studies done by Siah et al. (2015) and Abdul Khalil et al. (2007). Polysaccharide-based films commonly tend to absorb moisture, since they can form a hydrogen bond with other polymers (Othman et al. 2017). In this case, interfacial interactions between seaweed nanoparticles and matrix can cause be an increase in moisture content of agar-based biopolymer composite. Based on the result shown in Table 1, the moisture content of the biopolymer composite increased as the seaweed nanoparticles load increased from $4 \%$ to $6 \%$. However, the moisture content of the composite film slightly increased when the film was filled with from $6 \%$ to $8 \%$ seaweed nanoparticles load. The addition of the water absorption by the agar-based biopolymer composite was attributed to the presence of a higher amount of hydrophilic seaweed nanoparticles in the matrix. These results were similar to the results reported by Tabei et al. (2011), which were also supported by Kadam et al. (2015). They stated that the presence of a large number of hydroxyl groups, which tended to increase the hydrophilicity of the biopolymer composite.

Table 1. Physical Properties of Biopolymer Composite Films

\begin{tabular}{|c|c|c|c|}
\hline Seaweed Loadings (\%) & Thickness $(\mathrm{mm})$ & Density $\left(\mathrm{cm}^{-1} \mathrm{~g}^{-1}\right)$ & Moisture Content $(\%)$ \\
\hline $0.00^{*}$ & $0.074 \pm 0.0079^{\mathrm{a}}$ & $0.0137 \pm 0.0003^{\mathrm{a}}$ & $19.87 \pm 0.03^{\mathrm{b}}$ \\
\hline 4.00 & $0.086 \pm 0.0051^{\mathrm{a}}$ & $0.0145 \pm 0.0002^{\mathrm{a}}$ & $19.43 \pm 0.09^{\mathrm{b}}$ \\
\hline 6.00 & $0.098 \pm 0.0052^{\mathrm{a}}$ & $0.0151 \pm 0.0002^{\mathrm{a}}$ & $19.52 \pm 0.07^{\mathrm{b}}$ \\
\hline 8.00 & $0.106 \pm 0.0058^{\mathrm{a}}$ & $0.0158 \pm 0.0002^{\mathrm{a}}$ & $18.56 \pm 0.11^{\mathrm{a}}$ \\
\hline \multicolumn{4}{|l|}{} \\
\hline $\begin{array}{l}\text { Note: }{ }^{*} 0.00 \% \text { represents the control (neat agar film); values are represented as mean } \pm \\
\text { standard deviation; and the same letters in the same column denote no significant difference } \\
(p \text {-value is less than 0.05) }\end{array}$
\end{tabular}

According to Table 1, the density of the biopolymer composite increased when the seaweed nanoparticles content increased. This density reached its maximum value of $0.0158 \mathrm{~cm}^{-1} \mathrm{~g}^{-1}$ when $8 \%$ seaweed nanoparticles was incorporated with agar-based biopolymer composite. The addition of seaweed nanoparticles increased the density of the mixture. This finding indicated that good compatibility between the agar matrix and the seaweed nanoparticles was achieved, in which the density of the biopolymer composite 
was enhanced by the presence of seaweed nanoparticles. This phenomenon could be due to the increase in polymer content and uniform dispersion of the nanoparticles in the matrix, which could provide better filler-matrix interfacial interactions (Piyada et al. 2013; Zarina and Ahmad 2014; Rosamah et al. 2016).

\section{Water Vapor Barrier Properties}

Water vapor evaporation is another important parameter in packaging film that allows for the estimation of the product shelf-life. A lower moisture exchange rate between the film and the environment is normally preferred, since it indicates better moisture protection (Slavutsky et al. 2012). Water barrier properties are commonly measured using the water vapor permeability (WVP) and WVTR methods. Bedane et al. (2016) reported that WVP was independent of relative humidity, whereas WVTR depended on the temperature and the relative humidity. Nevertheless, this study used WVTR to measure the water barrier properties of the composite. The results showed that there were no apparent changes in the WVTR of the biopolymer composite since there were no significant differences after the addition of seaweed nanoparticles (as shown in Table 2). This indicated that the addition of seaweed nanoparticles did not affect the water vapor barrier properties of agar-based biopolymer composite. A previous study by Guvendiren et al. (2012) also mentioned that clay as a reinforcing filler did not improve the water vapor barrier properties of $\kappa$-carrageenan/locust bean gum composite film.

\section{Table 2. Water Barrier and Mechanical Properties of Biopolymer Composite} Films

\begin{tabular}{|c|c|c|c|}
\hline Seaweed Loadings (\%) & WVTR $\left(\mathrm{g} / \mathrm{m}^{2} / \mathrm{h}\right)$ & TS $(\mathrm{MPa})$ & Elongation $(\%)$ \\
\hline $0.00^{*}$ & $33.11 \pm 0.45^{\mathrm{a}}$ & $12.95 \pm 2.54^{\mathrm{a}}$ & $39.58 \pm 2.19^{\mathrm{a}}$ \\
\hline 4.00 & $31.25 \pm 2.15^{\mathrm{a}}$ & $16.62 \pm 5.22^{\mathrm{cd}}$ & $37.16 \pm 1.35^{\mathrm{a}}$ \\
\hline 6.00 & $31.05 \pm 2.04^{\mathrm{a}}$ & $19.25 \pm 1.11^{\mathrm{bc}}$ & $34.24 \pm 1.01^{\mathrm{a}}$ \\
\hline 8.00 & $30.86 \pm 2.56^{\mathrm{a}}$ & $18.47 \pm 2.89^{\mathrm{bc}}$ & $32.42 \pm 1.53^{\mathrm{a}}$ \\
\hline \multicolumn{4}{|l|}{$\begin{array}{l}\text { Note: }{ }^{*} 0.00 \% \text { represents the control (neat agar film); values are represented as mean } \pm \\
\text { standard deviation; and the same letters in the same column denote no significant difference } \\
\text { (p-value is less than 0.05) }\end{array}$} \\
\hline
\end{tabular}

According to the results presented in Table 2, and compared to the moisture contents in Table 1, WVTR showed no apparent correlation with moisture content. There were some changes in the moisture content of biopolymer composite with different seaweed nanoparticles loading; however, there were no significant differences with the increase in WVTR. This indicates that the increase in WVTR was more related to the level of relative humidity. Possibly, the high concentration of water molecules in the surroundings increased the WVTR of the agar-based biopolymer composite.

\section{Tensile Strength and Elongation}

Using mechanical properties to determine the film performance is equally important compared to water barrier properties, especially in packaging and biodegradable film industries. The films should be able to sustain certain stress and deformation, depending on the desired application (Guvendiren et al. 2012; Marvdashti et al. 2017). The results showed that the control biopolymer composite had the lowest mechanical strength compared to the biopolymer composite (Table 2). The addition of seaweed nanoparticles subsequently enhanced the mechanical strength of the biopolymer composite. The tensile strength (TS) significantly increased as the seaweed nanoparticles loading increased, up to 
$6 \%$ were loaded in the agar matrix. This shows that incorporating seaweed nanoparticles resulted in a strong mechanical reinforcing effect on the agar matrix. Possibly, the hydroxyl groups between the seaweed and agar facilitated strong intermolecular interaction, which contributed to a more effective load transfer (Wahab and Razak 2016). Therefore, further investigation was required. The addition of a $6 \%$ seaweed nanoparticles load appeared to attain the best TS in this study (Table 2), since it could sustain the highest load among all other composite films in this study due to its high rigidity and film stiffness.

The elongation measurement was used to determine the flexibility and stretchability of the films. The ability of the material to deform is crucial in producing flexible and elastic products in industries, e.g., food packaging, cosmetics, and agriculture (Sun et al. 2014; Wang and Qi 2010). Table 2 shows the increase in seaweed nanoparticles content decreased the elongation at break of all biopolymer composite. In contrast, the blank agarbased biopolymer composite exhibited the highest percentage of elongation, approximately $39.58 \%$. Previous studies by Abdul Khalil et al. $(2017 \mathrm{~b}, 2018)$ reported that the incorporation of seaweed nanoparticles reduced the flexibility (or increased the brittleness) of the biopolymer composite because the seaweed nanoparticles were more rigid than the agar matrix. As reported by Rosamah et al. (2016), an increase in nanoparticles content causes a decrease in the deformability of the interface between the nanoparticles. This phenomenon was attributed to a higher breaking tendency of the agar/seaweed nanoparticles composites. Additionally, it was found that the biopolymer composite with $8 \%$ nanoparticles seaweed loading had the lowest elongation value. The addition of nanoparticles increased the brittleness and caused the biopolymer composite to become more easily break, as discussed earlier.

\section{Surface Morphology}

For greater insight into the microscopic structure and homogeneity of the biopolymer composites, the surface morphology of the control and biopolymer composite were examined via scanning electron microscopy (Fig. 3). Incorporating seaweed nanoparticles (from $4 \%$ to $6 \%$ ) showed a smoother surface morphology, compared to the film with an $8 \%$ nanoparticles load (Figs. $3 b$ to d). From the analysis of the dispersion level seaweed nanoparticles, the homogeneity of the biopolymer composite, and the presence of agglomeration in the matrix, additions of up to $6 \%$ seaweed nanoparticles were well dispersed and distributed in the agar matrix (Figs. 3b and 3c). The texture of the film composites changed from smooth to rough, becoming more prominent as the seaweed nanoparticles filler load increased until $8 \%$. The addition of seaweed nanoparticles resulted in an uneven dispersion and agglomeration, due to the uneven distribution of the size and texture of the nanofiller particle (Koo 2006). This uneven dispersion and agglomeration were more clearly observed in the biopolymer composites with 8\% nanoparticles (Fig. 3d). The uneven dispersion also affected the tensile strength, elongation, and thickness of the agar-seaweed nanoparticles biopolymer composite. Because uneven dispersion of seaweed nanoparticles in the agar matrix, the nanoparticles are no able to form stronger interactions and adhesions on the interfaces of the filler and matrix, thus voids on its surface are formed. Hence, the mechanical properties of the biopolymer composite were decreased.

Piyada et al. (2013) and Sánchez-García et al. (2010) reported that the agglomeration of nanoparticles could thus result in poor interfacial stress transfer as a result of reducing the interfacial contact between the nanofillers and the matrix. Therefore, this finding showed that the mechanical strength of the biopolymer composite was decreased (Table 2). 

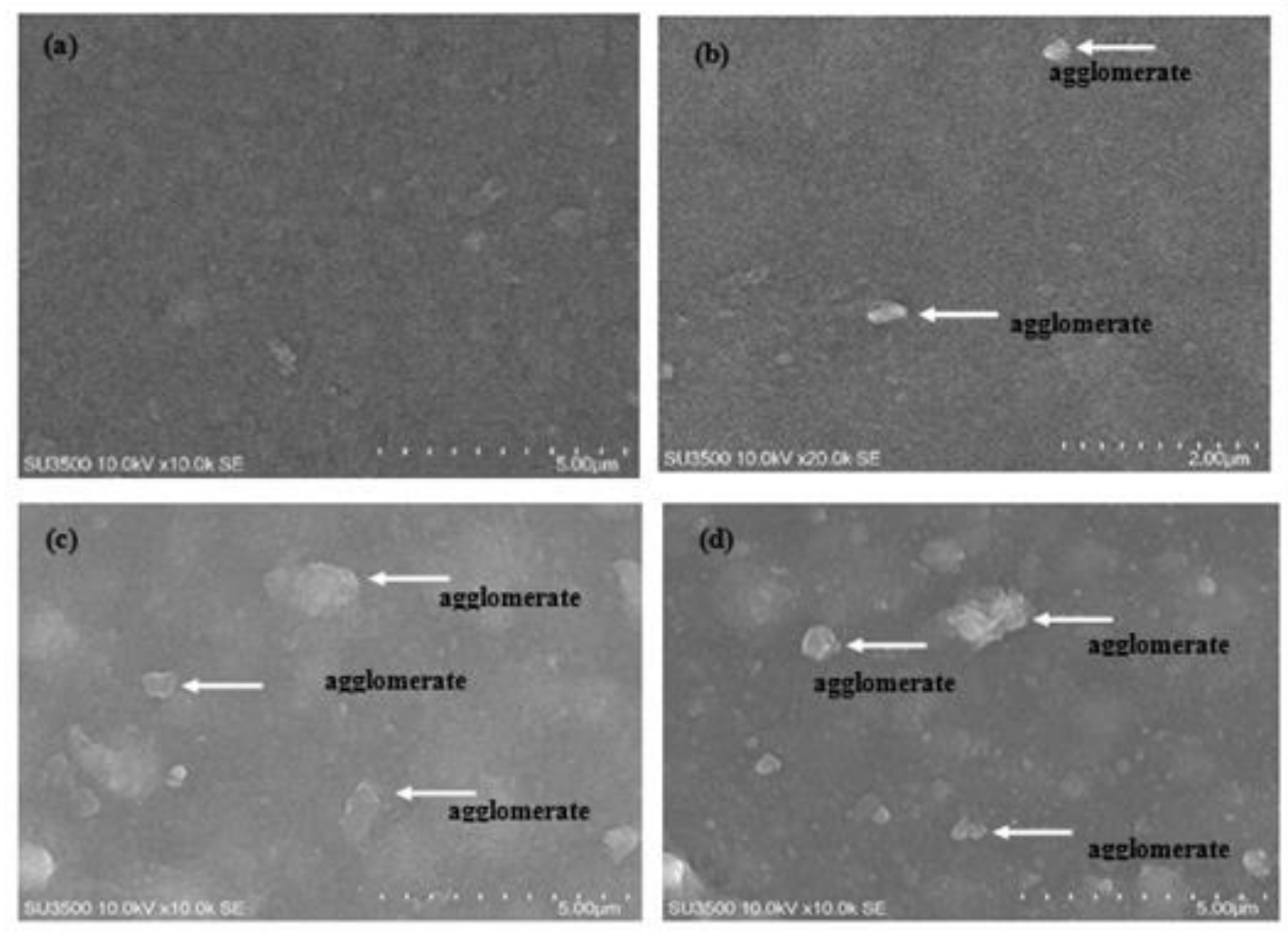

Fig. 3. Surface micrographs of the agar and biopolymer composites with different seaweed nanoparticles loads: (a) agar film (control); (b) 4\%; (c) 6\%; and (d) $8 \%$

\section{Biodegradability Properties}

The degradability of a composite is crucial when the polymeric system will be applied in daily lives. The faster the polymer material degrades, the greater the reduction on the environmental pollution load. Table 3 shows the results of the biodegradability test on the biocomposite samples. The percent weight reduction positively correlated with the nanoparticles load concentration (Table 3).

Table 3. Result of the Biodegradability Test of the Film Composites with Different Seaweed-Nanoparticle Loads

\begin{tabular}{|c|c|c|c|}
\hline Seaweed Loadings $(\%)$ & $W_{1}(\mathrm{mg})$ & $W_{\mathrm{H}}(\mathrm{mg})$ & Weight loss $(\%)$ \\
\hline $0.00^{\star}$ & $25.070 \pm 1.43^{\mathrm{a}}$ & $25.047 \pm 2.34^{\mathrm{a}}$ & $0.179 \pm 2.10^{\mathrm{a}}$ \\
\hline 4.00 & $24.717 \pm 2.05^{\mathrm{a}}$ & $24.654 \pm 3.25^{\mathrm{a}}$ & $0.255 \pm 0.43^{\mathrm{a}}$ \\
\hline 6.00 & $24.445 \pm 2.10^{\mathrm{a}}$ & $23.991 \pm 2.75^{\mathrm{a}}$ & $1.857 \pm 0.91^{\mathrm{a}}$ \\
\hline 8.00 & $19.954 \pm 2.76^{\mathrm{a}}$ & $19.142 \pm 1.04^{\mathrm{b}}$ & $4.069 \pm 1.68^{\mathrm{b}}$ \\
\hline
\end{tabular}

Note: ${ }^{\star} 0.00 \%$ represents the control (neat agar film); values are represented as mean \pm standard deviation; and the same letters in the same column denote no significant difference ( $p$-value is less than 0.05)

The increase in the nanoparticles load concentration increased the weight loss of the composite because a higher filler particle meant an increased cellulose content was available for aerobic degradation/ decomposition (Brebu 2020). The biopolymer composite with an $8 \%$ seaweed nanoparticles load had the highest weight decrease because it had the highest seaweed nanoparticles content amongst all samples, i.e., more fiber material available for decomposition. In conclusion, the incorporation of seaweed nanoparticles 
increased moisture absorption, and thereby it enhanced the biodegradability of the biofilm composite in the first 7 days of burial.

Based on the observations of the authors, the growth of fungi caused the biopolymer composite damage (Fig. 4). The fungus could grow on the biopolymer composite because of suitable environmental factors, e.g., humidity and temperature. The results of the soil burial and biopolymer characteristics test showed that mold overgrew the biopolymer composite with $8 \%$ seaweed nanoparticles. After burying the samples for three weeks, there was a major visual change in the surface's color of the biopolymer composite. The color of the control samples (without filler) faded more than the treated ones. Both biopolymer composites with and without seaweed nanoparticles showed their highest soil microbe degradation after three weeks of exposure. The extracellular microbe enzymes enabled it to penetrate deep into the biopolymer composite and act on the composite surface; the biodegradation of biopolymer composite products is usually a surface erosion process (Maran et al. 2014).

Similar results were also shown by the visual appearance of the biopolymer composite as a function of time buried in soil (Fig. 4). Regardless of the addition of seaweed nanoparticles, all the biopolymer composites showed significant degradation at 21 days of study. Even though, after the first 7 days, showing the beginning of degradation. The degradation process of biopolymer composites with $4 \%$ and $6 \%$ was significant at 14 days; while in the biopolymer composite with seaweed nanoparticles 8\%, 18 days were necessary. In soil burial, water diffuses into the biopolymer composite sample, causing swelling and enhancing biodegradation due to increases in microbial growths.

\begin{tabular}{|c|c|c|c|c|}
\hline $\begin{array}{l}\text { Seaweed load- } \\
\text { ings }(\%)\end{array}$ & 0 day & 7 days & 14 days & 21 days \\
\hline 0.00 & & & & \\
\hline 4.00 & & & & \\
\hline 6.00 & & & & \\
\hline 8.00 & & & & \\
\hline
\end{tabular}

Fig. 4. Biopolymer composite surfaces after soil burial from $0 \mathrm{~d}$ to $21 \mathrm{~d}$

The morphological changes in the soil burial test samples (before and after) were visualized via SEM micrographs and are shown in Fig. 5. The agar-based biopolymer composite with a seaweed nanoparticles surface was smooth before undergoing soil burial (Fig. 5a). Figure 5a shows the agar-based biopolymer composite with seaweed nanoparticles before degradation via SEM photography. Analysis of the samples was performed after $7 \mathrm{~d}, 14 \mathrm{~d}$, and $21 \mathrm{~d}$ of soil burial via SEM (Figs. 5b, 5c, and 5d, respectively) 
and showed that biopolymer composites began to be degraded by both bacterial and fungal strains within $7 \mathrm{~d}$ of exposure time (Iovino et al. 2008). Both bacteria and fungi used open ways to penetrate the biopolymer composite surface and caused voids with large holes on its surface. Therefore, the interior part of the blend was exposed, with the surface completely exposed after $21 \mathrm{~d}$ of biodegradation (as shown in Fig. 5d). Furthermore, Jumaidin et al. (2017) revealed that the rate of composite decomposition increases with an increase in nanoparticles concentration, because the addition of nanoparticles increases water absorption, thereby facilitating degradation of the composite via soil microbes. These observations may suggest that this material could be bio-assimilated by mixed soil consortia, which may act in a synergetic way and promote degradation.
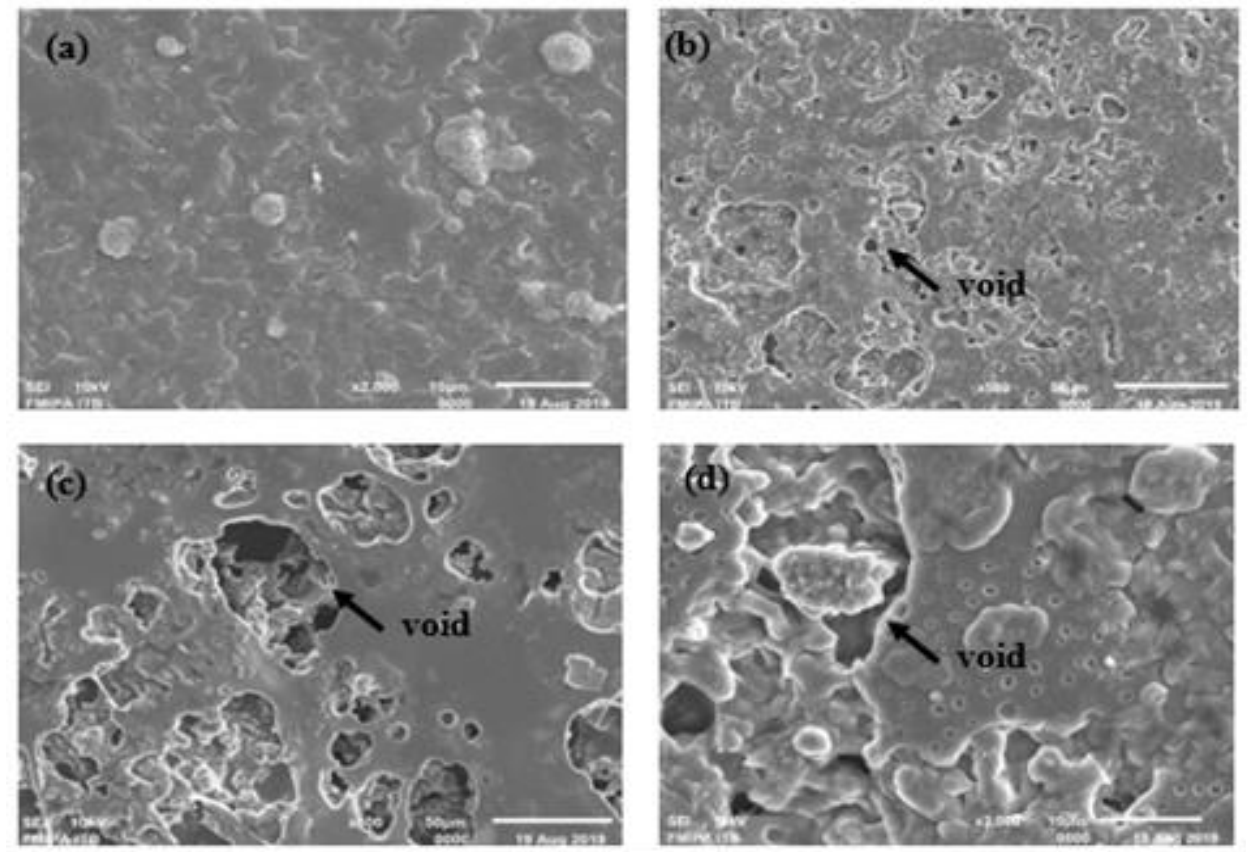

Fig. 5. Degradation behavior of the agar-based biopolymer composite with $6 \%$ seaweed nanoparticle subjected to a soil burial test at different degradation times analyzed via SEM micrographs: (a) $0 \mathrm{~d}$; (b) $7 \mathrm{~d}$; (c) $14 \mathrm{~d}$; and (d) $21 \mathrm{~d}$

\section{CONCLUSIONS}

1. When reinforced with seaweed nanoparticles, the physical, water vapor barrier, mechanical, and morphological properties of agar-based biopolymer were changed remarkably.

2. There were no apparent changes in the water vapour transmission rate (WVTR) of the biopolymer composite since there were no significant differences after the addition of seaweed nanoparticles.

3. Except for elongation, the mechanical properties of nano-seaweed/agar biopolymer composite increased with the increase in seaweed nanoparticles content.

4. The morphological properties analysis revealed no aggregations of fillers and an absence of void formation in the biopolymer composite when up to $6 \%$ seaweed nanoparticles was incorporated. 
5. The rate of biopolymer composite decomposition increases with an increase in nanoparticles concentration, as the SEM analysis revealed that the microbes has penetrate the biopolymer composite surface and caused voids on its surface.

6. Thus, agar-based biopolymer composite incorporated with seaweed nanoparticles can be used in industrial applications, e.g., food packaging to replace petrochemical-based plastics.

\section{ACKNOWLEDGMENTS}

The authors would like to thank the Institut Teknologi Bandung (ITB) for providing research grants through the Research, Community Services, and Innovation Program ((P3MI)-ITB No. 1106/I1.C02.2/KU/2020). The authors also appreciate the necessary testing facilities provided by the Instructional Laboratory, School of Life Sciences and Technology, ITB.

\section{REFERENCES CITED}

Abdel-Shafy, H. I., and Mansour, M. S. M. (2018). "Solid waste issue: Sources, composition, disposal, recycling, and valorization,' Egyptian Journal of Petroleum 27(4), 1275-1290. DOI: 10.1016/j.ejpe.2018.07.003

Abdul Khalil, H. P. S., Hanida, S., Kang, C. W., and Fuaad, N. A. N. (2007). "Agrohybrid composite: the effects on mechanical and physical properties of oil palm fiber (EFB)/glass hybrid reinforced polyester composites," Journal of Reinforced Plastics and Composites 26(2), 203-218. DOI: 0.1177/0731684407070027

Abdul Khalil, H. P. S., Tye, Y. Y., Chow, S. T., Saurabh, C. K., Paridah, T., Dungani, R., and Syakir, M. I. (2016). "Cellulosic pulp fiber as reinforcement materials in seaweed-based film," BioResources 12(1), 29-42. DOI: 10.15376/biores.12.1.29-42

Abdul Khalil, H. P. S., Tye, Y. Y., Ismail, Z., Leong, J. Y., Saurabh, C. K., Lai, T. K., Chong, E. W. N., Aditiawati, P., Paridah, T., and Dungani, R. (2017a). "Oil palm shell nanofiller in seaweed-based composite film: Mechanical, physical, and morphological properties," BioResources 12(3), 5996-6010. DOI:

10.15376/biores.12.3.5996-6010

Abdul Khalil, H. P. S., Tye, Y. Y., Saurabh, C. K., Leh, C. P., Lai, T. K., Chong, E. W. N., Fazita, M. R. N., Hafiidz J. M., Banerjee, A., and Syakir, M. I. (2017b).

"Biodegradable polymer films from seaweed polysaccharides: A review on cellulose as a reinforcement material," Express Polymer Letters 11(4), 244-265. DOI: 10.3144/expresspolymlett.2017.26

Abdul Khalil, H. P. S., Lai, T. K., Tye, Y. Y., Paridah, M. T., Nurul Fazita, M., R., Azniwati, A. A., Dungani, R., and Rizal, S. (2018). "Preparation and characterization of microcrystalline cellulose from sacred Bali bamboo as reinforcing filler in seaweed-based composite film," Fibers and Polymers 19, 423-434. DOI: 10.1007/s12221-018-7672-7

ASTM D374-99. (1999). "Standard test method for thickness of solid electrical insulation," ASTM International, West Conshohocken, PA.

ASTM D882-02. (2002). "Standard test method for tensile properties of thin plastic sheeting," ASTM International, West Conshohocken, PA. 
ASTM D5988-18. (2018). "Standard test method for determining aerobic biodegradation of plastic materials in soil," ASTM International, West Conshohocken, PA.

Bedane, A. H., Eić, M., Farmahini-Farahani, M., and Xiao, H. (2016). "Theoretical modeling of water vapor transport in cellulose-based materials," Cellulose 23, 15371552. DOI: 10.1007/s10570-016-0917-y

Brebu, M. (2020). "Environmental degradation of plastic composites with natural fillers A review," Polymers 12(1), 166-187. DOI: 10.3390/polym12010166

Food Agriculture Organization Fisheries and Aquaculture Information and Statistics Branch FAO-FIGIS. (2019). "FIGIS-Time series query on Aquaculture," Retrieved from http://www.fao.org/figis/servlet/SQservlet.htm on 27 April 2021.

Guvendiren, M., Soshinski, A. A., Gambogi, R. J., and Yang, S. (2012). "Calcium carbonate composite hydrogel films: Particle packing and optical properties," Polymer Engineering \& Science 52(6), 1317-24. DOI: 10.1002/pen.23077

Hubbe, M. A., Ferrer, A., Tyagi, P., Yin, Y., Salas, C., Pal, L., and Rojas, O. J. (2017). "Nanocellulose in thin films, coatings, and plies for packaging applications: A review," BioResources 12(1), 2143-233. DOI: 10.15376/biores.12.1.2143-2233

Huq, T., Salmieri, S., Khan, A., Khan, R. A., Tien, C. L., Riedl, B., Fraschini, C., Bouchard, J., Uribe-Calderon, J., Kamal, M. R., et al. (2012). "Nanocrystalline cellulose (NCC) reinforced alginate based biodegradable nanocomposite film," Carbohydrate Polymers 90(4), 1757-1763. DOI: 10.1016/j.carbpol.2012.07.065

Iovino, R., Zullo, R., Rao, M. A., Cassar, L., and Gianfreda, L. (2008). "Biodegradation of poly(lactic acid)/starch/coir biocomposites under controlled composting conditions," Polymer Degradation and Stability 93(1), 147-157. DOI: 10.1016/j.polymdegradstab.2007.10.011

Jumaidin, R., Sapuan, S. M., Jawaid, M., Ishak, M. R., and Sahari, J. (2017). "Effect of seaweed on mechanical, thermal, and biodegradation properties of thermoplastic sugar palm starch/agar composites," International Journal of Biological Macromolecules 99, 265-273. DOI: 10.1016/j.ijbiomac.2017.02.092

Kadam, S. U., Pankaj, S. K., Tiwari, B. K., Cullen, P. J., and O’Donnell, C. P. (2015). "Development of biopolymer-based gelatin and casein films incorporating brown seaweed Ascophyllum nodosum extract," Food Packaging and Shelf Life 6, 68-74. DOI: 10.1016/j.fpsl.2015.09.003

Koo, J. H. (2006). Polymer Nanocomposites: Processing, Characterization, and Applications, McGraw-Hill, New York, NY.

Leja, K., and Lewandowicz, G. (2010). "Polymer biodegradation and biodegradable polymers - A review," Polish Journal of Environmental Studies 19(2), 255-266.

Luan, L., Wu, W., Wagner, M.H., and Mueller, M. (2010). "Seaweed as novel biofiller in polypropylene composites," Journal of Applied Polymer Science 118(2), 997-1005. DOI: 10.1002/app.32462

Maran, J. P., Sivakumar, V., Thirugnanasambandham, K., and Sridhar, R. (2014). "Degradation behavior of biocomposites based on cassava starch buried under indoor soil conditions," Carbohydrate Polymers 101, 20-28. DOI: 10.1016/j.carbpol.2013.08.080

Marvdashti, L. M., Koocheki, A., Yavarmanesh, M. (2017). “Alyssum homolocarpum seed gum-polyvinyl alcohol biodegradable composite film: Physicochemical, mechanical, thermal and barrier properties," Carbohydrate Polymers 155, 280-293. DOI: $10.1016 /$ j.carbpol.2016.07.123

Merino, D., and Alvarez, V.A. (2020). "Green microcomposites from renewable 
resources: Effect of seaweed (Undaria pinnatifida) as filler on corn starch-chitosan film properties," Journal of Polymers and the Environment 28, 500-516. DOI: https://doi.org/10.1007/s10924-019-01622-9

Mierzwa-Hersztek, M., Gondek, K., and Kopeć, M. (2019). “Degradation of polyethylene and biocomponent-derived polymer materials: An overview," Journal of Polymers and the Environment 27, 600-611. DOI: 10.1007/s10924-019-01368-4

Othman, S. H., Edwal, S. A. M., Risyon, N. P., Basha, R. K., and Talib, R. A. (2017). "Water sorption and water permeability properties of edible film made from potato peel waste," Food Science and Technology 37(S1), 63-70. DOI: 10.1590/1678457x.30216

Paul, K. T., Satphaty, S. K., Manna, L., Chakraborty, K. K., and Nando, G. B. (2007). "Preparation and characterization of nano structured materials from fly ash: A waste from thermal power stations, by high energy ball milling," Nanoscale Research Letters 2, 397-404. DOI: 10.1007/s11671-007-9074-4

Phanthong, P., Reubroycharoen, P., Hao, X., Xu, G., Abudula, A., and Guan, G. (2018). "Nanocellulose: Extraction and application," Carbon Resources Conversion 1(1), 32 43. DOI: 10.1016/j.crcon.2018.05.004

Piyada, K., Waranyou, S., and Thawien, W. (2013). "Mechanical, thermal and structural properties of rice starch films reinforced with rice starch nanocrystals," International Food Research Journal 20(1), 439-449.

Rosamah, E., Hossain, M. S., Abdul Khalil, H. P. S., Wan Nadirah, W. O., Dungani, R., Nur Amiranajwa, A. S., Suraya, N. L. M., Fizree, H. M., and Mohd Omar, A. K. (2016). "Properties enhancement using oil palm shell nanoparticles of fibers reinforced polyester hybrid composites," Advanced Composite Materials 1-14. DOI: 10.1080/09243046.2016.1145875

Sánchez-García, M. D., Hilliou, L., and Lagarón, J. M. (2010). "Morphology and water barrier properties of nanobiocomposites of $\kappa / \mathrm{l}$-hybrid carrageenan and cellulose nanowhiskers," Journal of Agricultural and Food Chemistry 58(24), 12847-12857. DOI: $10.1021 / \mathrm{jf} 102764 \mathrm{e}$

Shankar, S., and Rhim, J. W. (2016). "Preparation of nanocellulose from microcrystalline cellulose: The effect on the performance and properties of agar-based composite films," Carbohydrate Polymers 135, 18-26. DOI: 10.1016/j.carbpol.2015.08.082

Shia, W. M., Aminah, A., and Ishak, A. (2015). "Edible films from seaweed (Kappaphycus alvarezii)," International Food Research Journal 22(6), 2230-2236.

Slavutsky, A. M., Bertuzzi, M. A., and Armada, M. (2012). "Water barrier properties of starch-clay nanocomposite films," Brazilian Journal of Food Technology 15(3), 208218. DOI: 10.1590/S1981-67232012005000014

Sorrentino, A., Gorrasi, G., and Vittoria, V. (2016). "Potential perspectives of bionanocomposites for food packaging applications," Trends in Food Science \& Technology 18(2), 84-95. DOI: 10.1016/j.tifs.2006.09.004

Sun, Q., Xi, T., Li, Y., and Xiong, L. (2014). "Characterization of corn starch films reinforced with $\mathrm{CaCO}_{3}$ nanoparticles," PLOS One 9(9), 1-6. DOI:

10.1371/journal.pone.0106727

Supriadi, A. (2016). "Inaplas soroti manajemen sampah dan pengelolaan dana plastik," (http://www.cnnindonesia.com/ekonomi/20160222123332-92-112525/inaplas-sorotimanajemen-sampah-dan-pengelolaan-dana-plastik/), Accessed 7 July 2020.

Swami, P. N., Raju, B. N., Rao, D. V., and Rao, J. B. (2009). "Sythensis and 
characyertization of nano-structred fly ash: A waste from thermal power plant," Journal of Nanomaterials, Nanoengineering and Nanosystems 223(2), 35-44. DOI: 10.1243/17403499JNN182

Tabei, Y., Tsutsumi, K., Ogawa, A., Era, M., and Morita, H. (2011). “Application of insoluble fibroin film as conditioning film for biofilm formation," Sensors and Materials 23(4), 195-205.

Usman, M. A., Momohjimoh, I., and Gimba, A. S. B. (2016). "Effect of groundnut shell powder on the mechanical properties of recycled polyethylene and its biodegradability," Journal of Minerals and Materials Characterization and Engineering 4(3), 228-240. DOI: 10.4236/jmmce.2016.43021

Wahab, L. F., and Razak, S. A. (2016). "Bionanocomposite film of kappacarrageenan/nanotube clay: Growth of hydroxyl apatite and model drug release," Digest Journal of Nanomaterials and Biostructures 11(3), 963-972.

Wang, W., and Qi, L. (2010). "Study on preparation and property of $\mathrm{CaCO}_{3}$-filled SF/PVA blend films," International Journal of Chemistry 2(1), 174-179. DOI: 10.5539/ijc.v2n1p174

Zarina, S., and Ahmad, I. (2014). "Biodegradable composite films based on $\kappa-$ carrageenan reinforced by cellulose nanocrystal from kenaf fibers," BioResources 10(1), 256-271.

Article submitted: December 23, 2020; Peer review completed: April 24, 2021; Revised version received and accepted: May 3, 2021; Published: May 28, 2021.

DOI: $10.15376 /$ biores.16.3.5118-5132 